\title{
Desempenho de novilhas Holandesas confinadas com dietas com diferentes níveis de monensina sódica
}

\author{
Marcus Vinicius Morais de Oliveira ${ }^{1}$, Rogério de Paula Lana ${ }^{2}$, Eduardo da Costa Eifert ${ }^{3}$, Dirce \\ Ferreira Luz ${ }^{1}$, Fernando Miranda de Vargas Junior ${ }^{1}$
}

\footnotetext{
1 Universidade Estadual de Mato Grosso do Sul - Unidade Universitária de Aquidauana.

2 Universidade Federal de Viçosa - Departamento de Zootecnia.

${ }^{3}$ Embrapa Arroz e Feijão - Santo Antônio de Goiás - GO.
}

\begin{abstract}
RESUMO - Objetivou-se avaliar a influência do ionóforo monensina sódica no consumo, no ganho de peso, na conversão alimentar e nas alturas de cernelha e garupa de novilhas em confinamento e determinar os custos com alimentação. Utilizaram-se 28 novilhas da raça Holandesa confinadas individualmente por 84 dias e alimentadas com dietas contendo 32,84\% de concentrado (grão de milho, farelo de soja, ureia e mistura mineral) e 67,16\% de silagem de milho e cana-de-açúcar, na proporção de 1:1 na matéria seca (MS). Ao concentrado foram adicionados quatro níveis de ionóforo $(0,14,28$ e $42 \mathrm{mg}$ de monensina/kg de MS da dieta oferecida), totalizando quatro dietas, em delineamento inteiramente casualizado, cada uma com sete repetições. A adição de monensina aumenta o custo das dietas e não influencia significativamente os consumos de matéria seca, proteína bruta e fibra em detergente neutro, o ganho de peso médio diário nem a conversão alimentar e as alturas de cernelha e de garupa.
\end{abstract}

Palavras-chave: bovinos, ionóforo, leiteiras, ruminantes

\section{Performance of Holstein heifers in feedlot receiving monensin at different levels}

\begin{abstract}
The objective of this study was to evaluate the influence of the ionophore monensin on the intake, weight gain, feed:gain ratio and withers and croup heights of heifers maintained in feedlot, and also the feeding costs. Twenty eight Holstein heifers were confined individually for 84 days, and fed diets containing 32.84\% concentrate (corn grain, soybean meal, urea and mineral mix) and $67.16 \%$ corn silage and sugar cane, at the proportion of 1:1 in DM. The ionophore levels added to the concentrate were $0,14,28$ and $42 \mathrm{mg}$ monensin/ $\mathrm{kg}$ DM of the offered diet, totaling four experimental diets. The experiment was analyzed as a randomized complete block design with four diets and seven replications. The monensin addition raised the cost of the diets, but the different monensin levels did not influence the dry matter intake, the crude protein and neutral detergent fiber intakes; the average daily gain; the feed:gain ratio; and the withers and croup heights.
\end{abstract}

Key Words: bovines, dairy cattle, ionophore, ruminant

\section{Introdução}

O desenvolvimento e o ganho de peso de novilhas leiteiras devem ser equilibrados. Portanto, o fornecimento de uma alimentação deficiente, que não supra sua necessidade nutricional, determina um atraso na vida reprodutiva e produtiva, tornando-a inviável economicamente (Sartori, 2007). Por outro lado, o fornecimento nessa fase de uma dieta com quantidade excessiva de nutrientes, principalmente de energia , também é prejudicial, pois promove aumento da deposição de gordura nos ovários e diminuição do tecido secretor (parênquima) da glândula mamária, comprometendo a reprodução e a futura produção de leite da novilha (Sejrsen et al., 1983). O plano de alimentação a ser adotado deve permitir que as novilhas atinjam o peso à puberdade e a concepção o mais cedo possível, sem que isso promova efeitos negativos em sua vida produtiva.

A deficiência proteica incide negativamente sobre o ganho de peso, atrasando o início da puberdade (Miranda et al., 2003), todavia, o consumo insuficiente de energia é provavelmente o principal fator nutricional relacionado à precocidade sexual (NRC, 2001). Assim, substâncias melhoradoras da eficiência alimentar, como os ionóforos, 
que promovam alterações na fermentação ruminal, podem ser úteis quando fornecidas a novilhas leiteiras mantidas em regime de confinamento.

Ionóforos, como a monensina sódica, são produtos da fermentação de vários actinomicetos, produzidos principalmente por bactérias do grupo Streptomyces cinnamonensis (Hobson \& Stewart, 1997). Apesar de a monensina ter pouca influência no ganho de peso diário de animais em confinamento, ela contribui melhorando o desempenho, pois proporciona mudança na população microbiana ruminal, com consequente alteração da fermentação e dos produtos da digestão microbiana (Lana, 1997), diminuindo as produções de metano e dos ácidos acético e butírico e aumentando as de ácido propiônico (McGuffey et al., 2001). Outros efeitos benéficos são a diminuição da degradação de aminoácidos (Russell \& Martin, 1984), o controle do pH ruminal, a elevação da digestibilidade aparente da dieta (Salles \& Lucci, 2000b) e o controle da eimeriose no intestino delgado (Barragry, 1992). Assim, o objetivo neste experimento foi avaliar a influência de diversos níveis de monensina sobre o desempenho de novilhas leiteiras em confinamento.

\section{Material e Métodos}

O experimento foi realizado nos Setores de Gado de Leite e de Nutrição Animal, ambos pertencentes ao Departamento de Zootecnia da Universidade Federal de Viçosa, em Viçosa, Minas Gerais. Foram utilizadas 28 novilhas da raça Holandesa (quatro puras de origem, duas 15/16 e uma 7/8, para cada dieta) com peso vivo médio inicial $245 \mathrm{~kg}$.

As novilhas foram mantidas em confinamento por 104 dias em um galpão de alvenaria, durante 20 dias de adaptação e três períodos de 28 dias para coleta de dados. Os animais ficaram alojados individualmente em baias de 2,20 $\times 4,00 \mathrm{~m}^{2}$, providas de cocho e bebedouro automático, com laterais em cordoalha de aço e piso de concreto coberto com casca de café, que era renovada semanalmente. Durante o período pré-experimental, os animais foram protegidos contra ecto e endoparasitos e receberam uma dose intramuscular das vitaminas A, D e E.

Todas as dietas eram isoproteicas e isoenergéticas, com 15,5\% de PB (proteína bruta) e 68\% de NDT (nutrientes digestíveis totais), e foram fornecidas aos animais duas vezes ao dia. As dietas foram compostas de $67,16 \%$ de silagem de milho e cana-de-açúcar, na proporção de 1:1 na MS (matéria seca), e 32,84\% de concentrado, composto por grão de milho, farelo de soja, ureia e mistura mineral (Tabela 1). Os níveis de ionóforo adicionados diretamente na mistura concentrada foram de 0,14, 28 e $42 \mathrm{mg}$ de monensina/kg de MS da dieta, totalizando quatro dietas, de modo que a única variação entre elas foi a quantidade de monensina.

O desempenho das novilhas foi determinado com base no consumo de matéria seca, expresso em kg/dia, porcentagem do peso vivo e em relação ao peso metabólico, e nos consumos de proteína bruta e fibra em detergente neutro, no ganho de peso médio diário, na conversão alimentar e nas alturas de cernelha e de garupa. Assim, tanto os alimentos oferecidos como as sobras, foram coletados diariamente, pesados e amostrados, e as amostras congeladas por 28 dias, formando uma amostra composta do período por animal. As análises dos teores de matéria seca, proteína bruta e fibra em detergente neutro foram realizadas posteriormente, segundo metodologia descrita por Silva \& Queiroz (2002). As medições das alturas de cernelha e de garupa (utilizando-se um hipômetro) e a pesagem das novilhas também foram realizadas em intervalos de 28 dias, estabelecendo-se um jejum de sólidos de 12 horas.

O cálculo dos custos das dietas foram feitos considerando como despesas gerais apenas os gastos com medicamentos e com a alimentação em cada dieta. Não foram considerados despesas as instalações, os fluxos de serviços, as máquinas empregadas, as depreciações em geral e os gastos com a mão-de-obra. O preço dos insumos foi determinado de acordo com os valores aplicados em casas agropecuárias, no entanto, esses valores foram convertidos em dólar corrente.

Tabela 1 - Composição percentual de ingredientes e teores de proteína bruta, nutrientes digestíveis totais, cálcio e fósforo das dietas experimentais

\begin{tabular}{|c|c|}
\hline Ingrediente & Participação na dieta ${ }^{1}$ \\
\hline Silagem de milho (\%) & 33,58 \\
\hline Cana-de-açúcar (\%) & 33,58 \\
\hline Milho grão (\%) & 15,16 \\
\hline Farelo de soja (\%) & 15,84 \\
\hline Ureia (\%) & 1,29 \\
\hline Sulfato de amônia (\%) & 0,11 \\
\hline Mistura mineral $(\%)^{2}$ & 0,44 \\
\hline Total (\%) & 100,00 \\
\hline Proteína bruta (\% na MS) & 15,50 \\
\hline Nutrientes digestíveis totais (\% na MS) & 68,00 \\
\hline Cálcio (\% na MS) & 0,41 \\
\hline Fósforo (\% na MS) & 0,30 \\
\hline \multicolumn{2}{|c|}{$\begin{array}{l}1 \text { Foram adicionados } 0,38,76 \text { ou } 114 \mathrm{~g} \text { de Rumensin }{ }^{\circledR} / 100 \mathrm{~kg} \text { de mistur } \\
\text { concentrada, correspondendo às dietas com } 0,14,28 \text { e } 42 \mathrm{mg} \text { de monensina/kg } \\
\text { de MS. } \\
{ }^{2} \text { Mistura mineral contendo em cada } \mathrm{kg}: 25 \mathrm{~g} \text { de sulfato de amônio, } 75 \mathrm{~g} \text { de cloret } \\
\text { de potássio, } 425 \text { g de fosfato bicálcico, } 250 \text { g de calcário calcítico, 209,85 g de } \\
\text { sal comum, } 12,5 \text { g de sulfato de zinco, } 2,5 \mathrm{~g} \text { de sulfato de cobre e } 0,15 \mathrm{~g} \text { de sulfatc } \\
\text { de cobalto. }\end{array}$} \\
\hline
\end{tabular}


As análises das variáveis referentes ao desempenho das novilhas foram analisadas em delineamento inteiramente casualizado com quatro tratamentos e sete repetições, considerando cada novilha uma unidade experimental. Os dados foram interpretados por análise de variância e estudos de regressão, pelo pacote estatístico SAS (2003).

\section{Resultados e Discussão}

Não foi verificada neste trabalho influência significativa do nível de monensina sobre os consumos de matéria seca em kg/dia, em porcentagem do peso vivo e relação ao peso metabólico (Tabela 2). Os níveis de monensina não influenciaram ainda os teores de proteína bruta e fibra em detergente neutro (Tabela 2). De acordo com o NRC (2001), em novilhas leiteiras, a ingestão de alimentos não é significativamente alterada pela suplementação com ionóforos. Entretanto, pesquisadores (O’Kelly \& Spiers, 1992; Casey et al., 1994; Stock et al., 1995; Lana \& Fox, 2001) verificaram reduções na ingestão de matéria seca na ordem de até $6 \%$ ao fornecerem ionóroforos a novilhos de corte mantidos em regime de confinamento.

Numericamente, observou-se redução média de 3,4\% do consumo de matéria seca, em kg/dia, entre os animais mantidos com as dietas contendo monensina. Raun (1992) também mencionou diminuições na ingestão de matéria seca em torno de 4,0\%. Outros autores, como Goodrich et al. (1984), relataram que, em animais mantidos com dietas com $40 \%$ de concentrado, a monensina promovia reduções de até 6,4\% na ingestão de alimentos. Restle et al. (2001), ao fornecerem $13 \mathrm{mg}$ de monensina/kg MS a novilhas em confinamento, verificaram reduções de apenas $1,7 \%$ no consumo. Salles \& Lucci (2000a), no entanto, contrariando a maioria dos resultados, observaram aumento quadrático no consumo de matéria seca ao fornecerem a bezerros holandeses $0 ; 0,4 ; 0,8$ e 1,2 $\mathrm{mg}$ de monensina/kg de peso vivo, com ingestão máxima no nível de 0,8 mg de monensina.

Da mesma forma que o consumo de matéria seca, o ganho de peso médio diário e a eficiência alimentar, apesar de também serem favorecidos pelo consumo de ionóforos, igualmente não apresentaram diferenças significativas. De acordo com o NRC (2001), uma das vantagens no fornecimento de monensina a novilhas leiteiras é a melhora no desempenho reprodutivo.

Chalupa (1977), em revisão de uma série de experimentos sobre os efeitos da monensina no desempenho de bovinos, observou que, nos estudos de confinamento, animais que receberam monensina (5,5 a $33 \mathrm{mg}$ de monensina/kg de alimento ofertado) consumiram menos alimentos, mas mantiveram o ganho de peso e que essas reduções geralmente foram maiores durante as quatro primeiras semanas após o fornecimento de monensina. Em animais mantidos em pastagem ou que receberam forragem verde picada no cocho, a adição de 50 a 300 mg monensina/dia ocasionou aumento de cerca de $20 \%$ no ganho de peso. Nesses ensaios, independentemente do regime alimentar, a eficiência alimentar também melhorou. Outras influências da monensina em animais em confinamento são: redução na relação acetato:propionato (Raun, 1992), aumento da concentração de ácido propiônico, diminuição da produção de metano e amônia (Badawy et al., 1996), melhora na digestibilidade dos alimentos (Wedegaertner \& Johnson, 1983) e controle de coccidiose (Paisley \& Horn, 1996). Aparentemente, em todos os experimentos, o aumento da energia disponível, favorecido principalmente pela elevação do ácido propiônico, e a redução da produção dos gases metano e carbônico, diminuíram o consumo (melhorando a digestibilidade) nos animais, em decorrência de uma regulação do balanço

Tabela 2 - Desempenho de novilhas leiteiras recebendo dietas com diversos níveis de monensina

\begin{tabular}{|c|c|c|c|c|c|c|}
\hline \multirow[t]{2}{*}{ Item } & \multicolumn{4}{|c|}{ Nível de monensina na dieta } & \multirow[t]{2}{*}{ Erro-padrão } & \multirow[t]{2}{*}{ Média gera } \\
\hline & $0 \mathrm{mg}$ & $14 \mathrm{mg}$ & $28 \mathrm{mg}$ & $42 \mathrm{mg}$ & & \\
\hline Peso vivo inicial (kg) & $245,60 a$ & $245,60 \mathrm{a}$ & $243,90 a$ & $246,30 a$ & 3,94 & 245,35 \\
\hline Peso vivo final (kg) & $338,30 a$ & $332,10 \mathrm{a}$ & $341,30 \mathrm{a}$ & $335,40 a$ & 4,40 & 336,78 \\
\hline Consumo de matéria seca (kg MS/animal.dia) & $6,88 \mathrm{a}$ & $6,60 \mathrm{a}$ & $6,69 a$ & $6,65 a$ & 0,46 & 6,71 \\
\hline CMSPV (kg MS/100 kg PV) & $2,36 a$ & $2,28 \mathrm{a}$ & $2,29 a$ & $2,29 a$ & 0,09 & 2,31 \\
\hline CMSPM (g MS/PV $\left.{ }^{0,75}\right)$ & $97,37 \mathrm{a}$ & $94,14 \mathrm{a}$ & $94,54 \mathrm{a}$ & $94,39 \mathrm{a}$ & 2,91 & 95,11 \\
\hline Consumo de proteína bruta (kg/dia) & $1,10 \mathrm{a}$ & $1,14 \mathrm{a}$ & $1,09 \mathrm{a}$ & $1,12 \mathrm{a}$ & 0,07 & 1,11 \\
\hline Consumo de fibra em detergente neutro (kg/dia) & $2,42 \mathrm{a}$ & $2,24 \mathrm{a}$ & $2,35 a$ & $2,29 a$ & 0,17 & 2,33 \\
\hline Ganho médio diário (kg/dia) & $1,10 \mathrm{a}$ & $1,03 \mathrm{a}$ & $1,16 \mathrm{a}$ & $1,06 \mathrm{a}$ & 0,06 & 1,09 \\
\hline Conversão alimentar & $6,2 \mathrm{a}$ & $6,4 \mathrm{a}$ & $5,8 \mathrm{a}$ & $6,3 \mathrm{a}$ & 0,43 & 6,20 \\
\hline GCe - cm & $8,79 a$ & $7,37 a$ & $7,46 a$ & $8,67 a$ & 0,93 & 8,07 \\
\hline GGa - cm & $8,89 a$ & $7,44 \mathrm{a}$ & $7,41 \mathrm{a}$ & $8,19 a$ & 1,01 & 7,98 \\
\hline
\end{tabular}

Médias seguidas de letras iguais, na linha, não diferem $(\mathrm{P}>0,05)$ entre si pelo teste Tukey.

CMSPV = consumo de matéria seca em porcentagem do peso vivo; CMSPM = consumo de matéria seca em função do peso metabólico; GCe = ganho em altura de cernelha; GCA = ganho em altura da garupa. 
energético corporal, uma vez que essa energia é usada como um ganho adicional.

Segundo Bergen \& Bates (1984), o fornecimento de monensina a bovinos em confinamento influencia o ganho de peso diário, que pode variar de 96 a 110\% em relação a animais que não recebem suplemento. Nesta pesquisa, o peso vivo final e o ganho de peso médio diário não foram influenciados pelo consumo de monensina (Tabela 2). Meinert et al. (1992) forneceram a novilhas holandesas 200 mg de monensina/cabeça.dia e também não observaram efeitos significativos da monensina sobre o peso vivo e o ganho de peso diário, mas houve, no entanto, diminuição significativa da idade à primeira concepção e ao primeiro parto. Assim, esses autores concluíram que a monensina pode reduzir a idade à puberdade sem afetar o peso vivo e o escore corporal.

Apesar de o ionóforo não ter alterado significativamente o ganho de peso diário, numericamente, observou-se aumento de 5,4\% no ganho de peso entre as novilhas mantidas com a dieta contendo $28 \mathrm{mg}$ de monensina em comparação àquelas que receberam a dieta controle(Tabela 2). Aumentos no ganho de peso inferiores ao deste trabalho proporcionados pela monensina, de 1,6; 1,8 e 3,1\%, foram descritos por Goodrich etal.(1984), Raun(1992)eRestle(2001), respectivamente. Salles et al. (2001), no entanto, forneceram monensina a bezerras holandesas em crescimento e observaram maior ganho de peso diário (26,56\% superior aos animais controle).

As novilhas que receberam $42 \mathrm{mg}$ monensina apresentaram ganhos de peso inferiores aos daquelas que receberam $28 \mathrm{mg}$ de monensina: 96,36 e 105,45\%, respectivamente, em relação às novilhas controle (Tabela 2). Salles \& Lucci (2000a), no entanto, encontraram efeito quadrático da monensina sobre o ganho de peso, que melhorou 23,3; 28,9 e 17,6\% nos níveis 0,4; 0,8 e 1,2 mg de monensina/kg peso vivo, respectivamente, em relação aos animais controle.

Parte da melhora da conversão alimentar, observada em animais que recebem monensina, está relacionada à diminuição da produção dos gases metano e carbônico, uma vez que esses gases são gerados em reações durante o processo de síntese dos ácidos acético e butírico (Haddad \& Lourenço, 1977). No entanto, essa melhora também pode ser atribuída à diminuição da fermentação ruminal da proteína alimentar, que eleva consequentemente o aporte de peptídeos e aminoácidos no intestino delgado e aumenta a digestibilidade (McGuffey et al., 2001) e o controle de microrganismos causadores de eimeriose - coccidiose no intestino delgado (Barragry, 1992).
Neste experimento, a monensina não influenciou significativamente a conversão alimentar (Tabela 2), mas ocasionou redução de $6,4 \%$ na conversão alimentar dos animais que receberam a dieta com $28 \mathrm{mg}$ de monensina, em relação à dieta sem monensina, uma consequência da leve redução do consumo associada ao pequeno aumento no ganho de peso, culminando melhor utilização da energia da dieta. Outros autores (Bergen \& Bates, 1984; Goodrich et al., 1984; Raun, 1992; Restle, 2001), de forma semelhante, observaram aumentos de 5-12; 7,5; 5,6 e 5,5\% na eficiência alimentar. Foi verificada também piora na conversão alimentar (Tabela 2) nas novilhas que receberam $42 \mathrm{mg}$ de monensina, em relação às que receberam $28 \mathrm{mg}$ de monensina. Salles \& Lucci (2000a) não notaram mudanças na conversão alimentar ao fornecerem a bezerros 0; 0,4; 0,8 e 1,2 mg de monensina/kg de peso vivo.

As alturas de cernelha e de garupa isoladamente não indicam se o crescimento corporal e a maturação fisiológica das novilhas estão sendo adequados, porém, se utilizadas em conjunto com outros parâmetros zootécnicos, podem auxiliar na avaliação do desenvolvimento desses animais. Neste trabalho o fornecimento de monensina não influenciou significativamente as alturas de cernelha e garupa (Tabela 2). Meinert et al. (1992) estudaram o crescimento de novilhas holandesas e também não observaram efeitos significativos da monensina sobre o ganho em altura de cernelha. Todavia, outros autores (Salles \& Lucci, 2000a; Salles et al., 2001) relataram que a adição de monensina promove melhora desta variável.

A recria de novilhas leiteiras em regime de confinamento tem vários benefícios, como menor incidência de ecto e endoparasitos, maior domínio da parte nutricional e melhor controle do ganho de peso e do crescimento dos animais. Desse modo, o desenvolvimento adequado e a precoce maturação dos órgãos reprodutivos antecipam o primeiro parto e melhoram a produção de leite durante a vida útil da futura vaca. No entanto, as maiores desvantagens são os altos custos de produção, principalmente da alimentação, um fator decisivo no aspecto financeiro.

Como forma de reduzir os custos, alimentos mais baratos, como a cana-de-açúcar, que produz grande quantidade de matéria seca por hectare, se possível, devem ser incluída na dieta dos animais. Outros ingredientes, como os ionóforos, apesar de possuírem preço elevado também têm sido incluídos na dieta de animais em confinamento com o propósito de diminuir o consumo e melhorar a conversão alimentar, reduzindo o custo da dieta. Portanto, a análise econômica das dietas utilizadas é fundamental para avaliar a viabilidade de criação dos animais nesse regime. 
Na análise dos custos relativa à alimentação (Tabela 3), evidenciou-se que o ionóforo elevou o custo do confinamento. No entanto, a adição de $28 \mathrm{mg}$ de monensina promoveu benefício de 1,43\% em relação à dieta controle, com lucro de 1 centavo de dólar para cada quilo de peso vivo adquirido, um reflexo da leve redução no consumo de matéria seca associado ao pequeno aumento no ganho de peso diário. Essa diferença aparentemente insignificante passa a ser relevante quando se alimenta um grande número de animais, como acontece nos confinamentos dos Estados Unidos - mais de 100.000 cabeças, o que justifica nesse país a incorporação da monensina na dieta dos animais. Todavia, no Brasil, como o número de animais que recebem alimentação diretamente no cocho é pequeno, possivelmente os benefícios com a utilização de monensina não se refletirão de forma significativa na despesa final. Menor custo por quilo de ganho de peso para novilhas que receberam monensina também foi relatado por Restle et al. (2001). Salles \& Lucci (2000a), do mesmo modo, também observaram resultados satisfatórios na avaliação econômica de animais que receberam monensina.

Tabela 3- Análise de custo relativa à alimentação, em dólares

\begin{tabular}{|c|c|c|c|c|c|}
\hline \multirow[t]{2}{*}{ Item } & \multicolumn{4}{|c|}{ Tratamento - mg monensina/kg MS oferecido } & \multirow[b]{2}{*}{ Média } \\
\hline & $0 \mathrm{mg}$ & $14 \mathrm{mg}$ & $28 \mathrm{mg}$ & $42 \mathrm{mg}$ & \\
\hline Ganho peso total/animal - kg & 92,70 & 86,50 & 97,40 & 89,10 & 91,43 \\
\hline Ganho peso total/tratamento - kg & 648,90 & 605,50 & 681,80 & 623,70 & 640,01 \\
\hline Consumo MS total/animal - kg & 577,92 & 554,40 & 561,96 & 558,60 & 563,64 \\
\hline Consumo MS total/tratamento - kg & $4.045,44$ & $3.880,80$ & $3.933,72$ & $3.910,20$ & $3.945,48$ \\
\hline Consumo MN total/tratamento - kg & $10.692,57$ & $10.257,96$ & $10.398,40$ & $10.336,80$ & $10.421,43$ \\
\hline \multicolumn{6}{|l|}{ Volumoso - kg } \\
\hline Silagem de milho & $4.377,89$ & $4.199,72$ & $4.256,99$ & $4.231,53$ & $4.266,53$ \\
\hline Cana-de-açúcar & $4.793,43$ & $4.598,35$ & $4.661,06$ & $4.633,19$ & $4.671,51$ \\
\hline \multicolumn{6}{|l|}{ Concentrado - kg } \\
\hline Milho grão & 709,33 & 680,46 & 689,74 & 685,62 & 691,29 \\
\hline Farelo de soja & 737,44 & 707,43 & 717,07 & 712,79 & 718,68 \\
\hline Ureia & 52,19 & 50,06 & 50,74 & 50,44 & 50,86 \\
\hline Sulfato de amônia & 4,53 & 4,35 & 4,41 & 4,38 & 4,42 \\
\hline Mistura mineral & 17,76 & 17,04 & 17,27 & 17,17 & 17,31 \\
\hline Rumensin ${ }^{\circledR} 100$ - gramas & 0,00 & 554,55 & $1.124,22$ & $1.676,25$ & 838,76 \\
\hline \multicolumn{6}{|l|}{ Despesas - dólar U\$ } \\
\hline Vermífugo & 1,07 & 1,07 & 1,07 & 1,07 & 1,07 \\
\hline Vitaminas (A, D, E) & 0,70 & 0,70 & 0,70 & 0,70 & 0,70 \\
\hline \multicolumn{6}{|l|}{ Volumoso - kg } \\
\hline Silagem de milho & 45,45 & 43,60 & 44,19 & 43,93 & 44,29 \\
\hline Cana-de-açúcar & 16,59 & 15,91 & 16,13 & 16,03 & 16,17 \\
\hline \multicolumn{6}{|l|}{ Concentrado - kg } \\
\hline Milho grão & 81,00 & 77,70 & 78,76 & 78,29 & 78,94 \\
\hline Farelo de soja & 165,86 & 159,11 & 161,28 & 160,32 & 161,64 \\
\hline Ureia & 12,64 & 12,13 & 12,29 & 12,22 & 12,32 \\
\hline Sulfato de amônia & 0,55 & 0,53 & 0,53 & 0,53 & 0,54 \\
\hline Mistura mineral & 2,77 & 2,65 & 2,69 & 2,67 & 2,70 \\
\hline Rumensin ${ }^{\circledR} 100$ & 0,00 & 7,67 & 15,56 & 23,20 & 11,60 \\
\hline Despesa total/tratamento - dólar U\$ & 326,63 & 321,07 & 333,2 & 338,96 & 329,97 \\
\hline Despesa total/animal - dólar U\$ & 46,66 & 45,87 & 47,60 & 48,42 & 47,14 \\
\hline Despesa/animal/dia - dólar U\$ & 0,56 & 0,55 & 0,57 & 0,58 & 0,56 \\
\hline Custo/kg de ganho peso - dólar U\$ & 0,50 & 0,53 & 0,49 & 0,54 & 0,52 \\
\hline Benefício* & - & $-2,33$ & 1,43 & $-3,57$ & - \\
\hline
\end{tabular}

Duração do período de alimentação no confinamento: 84 dias.

Rumensin ${ }^{\circledR} 100$ - Nome comercial do ionóforo monensina. Composição: 10\% de monensina e $90 \%$ de farinha de milho, óleo vegetal, farelo de soja extrusado e casca de arroz moído.

1 U\$ dólar comercial $=2,89 \mathrm{R} \$$ reais.

* Benéfico: [(dieta controle - dieta referência)*ganho peso total].

\section{Conclusões}

A adição de monensina sódica na dieta de novilhas holandesas em confinamento eleva o custo da alimentação e não influencia os consumos de matéria seca, proteína bruta e fibra em detergente neutro nem o ganho de peso médio diário, a conversão alimentar e as alturas de cernelha e garupa. 


\section{Literatura Citada}

BADAWY, S.A.; YOUNIS, M.; SHALASH, M.R. et al. Monensin effects on rumen metabolic profile, methane production and protozoal population in buffalo-heifers. Egyptian Journal of Veterinary Science, v.30, p.49-56, 1996.

BARRAGRY, T.B. Treatment of coccidiosis in lambs. Irish Veterinary News, v.14, n.1, p.18-20, 1992.

BERGEN, W.G.; BATES, D.B. Ionophores: Their effect on production, efficiency and mode of action. Journal of Animal Science, v.58, p.1465-1483, 1984.

CASEY, N.H.; WESSELS, R.H.; MEISSNER, H.H. Feedlot growth performance of steers on salinomycin, monensin and a daily rotation between the two. Journal of the South African Veterinary Association, v.65, n.4, p.160-163, 1994.

CHALUPA, W. Manipulating ruminal fermentation. Journal of Animal Science, v.45, p.585-599, 1977.

GOODRICH, R.D.; GARRETT, J.E.; GAST, D.R. et al. Influence of monensin on the performance of cattle. Journal of Animal Science, v.58, n.6, p.1484-1498, 1984.

HADDAD, C.M.; LOURENÇO JÚNIOR., J.B. Monensina: um novo aditivo na alimentação de ruminantes. Zootecnia, v.15, n.3, p.171-181, 1977.

HOBSON, P.N.; STEWART, C.S. The rumen microbial ecosystem. 2.ed. New York: Blackie Academic \& Professional, 1997. 719p.

LANA, R.P. Effects of monensin on ruminal bacteria, ruminal fermentation and feedlot performance. 1997. $87 \mathrm{f}$. Dissertation (Doctor in Philosophy) - University Cornell, 1997.

LANA, R.P.; FOX, D.G. Interações entre monensina sódica, óleo de soja e fontes de nitrogênio no desempenho de novilhos Aberdeen Angus em confinamento. Revista Brasileira de Zootecnia, v.30, n.1, p.247-253, 2001.

McGUFFEY, R.K.; RICHARDSON, L.F.; WILKINSON, J.I.D. Ionophores for dairy cattle: Current status and future outlook. Journal of Dairy Science, v.84, p.194-203, 2001 (suppl.).

MEINERT, R.A.; YANG, C.M.J.; HEINRICHS, A.J.; et al. Effect of monensin on growth, reproductive performance, and estimated body composition in Holstein heifers. Journal of Dairy Science, v.75, n.1, p.257-261, 1992.

MIRANDA, J.E.C.; RIBEIRO, A.C.C.L.; CAMPOS, O.F. et al. Cria e recria de fêmeas leiteiras: passo a passo. Juiz de Fora: Embrapa Gado de Leite, 2003. p.6. (Comunicado Técnico, 30).

NATIONAL RESEARCH COUNCIL - N.R.C. Nutrient requirements of dairy cattle. 7.rev.ed. Washington, D.C.: National Academy Press, 2001. 381p.

O'KELLY, J.C.; SPIERS, W.G. Effect of monensin on methane and heat productions of steers fed lucene hay either ad libitum or at the rate of 250 g/hour. Australian Journal of Agricultural Research, v.43, n.8, p.1789-1793, 1992.

PAISLEY, S.I.; HORN, G.W. Feed intake of lightweight, earlyweaned beef and dairy calves fed receiving diets containing increasing levels of monensin. Oklahoma: Oklahoma State University, Agricultural Experiment Station, 1996. p.98-103. (Animal Science Research Report).

RAUN, A.P. Rumensin; "then and now". In: RUMENSIN "IN THE 1990's”, 1990, Dallas. Proceedings... Indianapolis: Elanco Animal Health, 1992. p.A1-A20.

RESTLE, J.; NEUMANN, M.; ALVES FILHO, D.C. et al. Terminação em confinamento de vacas e novilhas sob dietas com ou sem monensina sódica. Revista Brasileira de Zootecnia, v.30, n.6, p.1801-1812, 2001.

RUSSELL, J.B.; MARTIN, S.A. Effects of various methane inhibitors on the fermentation of amino acids by mixed rumen microorganisms in vitro. Journal of Animal Science, v.59, p.1329-1338, 1984.

SALLES, M.S.V.; LUCCI, C.S. Monensina para bezerros ruminantes em crescimento acelerado. 1. Desempenho. Revista Brasileira de Zootecnia, v.29, n.2, p.573-581, 2000a.

SALLES, M.S.V.; LUCCI, C.S. Monensina para bezerros ruminantes em crescimento acelerado. 2. Digestibilidade e parâmetros ruminais. Revista Brasileira de Zootecnia, v.29, n.2, p.582-588, 2000b.

SALLES, M.S.V.; ZANETTI, M.A.; CONTI, R.M.C. et al. Efeitos da monensina no desempenho de bezerras leiteiras em crescimento. Revista Brasileira de Zootecnia, v.30, n.4, p.1293-1298, 2001.

SARTORI, R. Manejo reprodutivo da fêmea leiteira. Revista Brasileira de Reprodução Animal, v.31, n.2, p.153-159, 2007.

SEJRSEN, K.; HUBER, J.T.; TUCKER, H.A. Influence of amount fed on hormone concentrations and their relationship to mammary growth in heifers. Journal of Dairy Science, v.66, n.4, p.845-855, 1983.

SILVA, D.J.; QUEIROZ, A.C. Análise de alimentos: métodos químicos e biológicos. 3.ed. Viçosa, MG: Imprensa Universitária, 2002. 235p.

STATISTICAL ANALYSIS SYSTEM - SAS. User's guide. Cary: SAS Institute, 2003. 2694p.

STOCK, R.A.; LAUDERT, S.B.; STROUP, W.W. et al. Effect of monensin and monensin and tylosin combination on feed intake variation of feedlot steers. Journal of Animal Science, v.73, p. 39-44, 1995.

WEDEGAERTNER, T.C.; JOHNSON, D.E. Monensin effects on digestibility, methanogenesis and heat increment of a cracked corn-silage diet fed to steers. Journal of Animal Science, v.57, p.168-177, 1983 